carrier state and the incidence of postoperative complications. N Engl J Med 1959;260:1303-1308.

13. Luzar MA, Coles GA, Faller B, et al. Staphylococcus aureus nasal carriage and infection in patients on continuous ambulatory peritoneal dialysis. N Engl J Med 1990;322:505-509.

14. Boelaert JR, DeSmedt RA, De Baere YA, et al. The influence of calcium mupirocin nasal ointment on the incidence of Staphylococcus aureus infections in hemodialysis patients. Nephrol Dial Transplant 1989;4:278-281.

15. Holton DL, Nicolle LE, Diley D, Bernstein K. Efficacy of mupirocin nasal ointment in eradicating Staphylococcus aureus nasal carriage in chronic hemodialysis patients. J Hosp Infect 1991;17:133-137.

16. Bulanda M, Gruszka M, Heczko B. Effect of mupirocin on nasal carriage of Staphylococcus aureus. J Hosp Infect 1989;14:117-124.

17. Doebbeling BN, Breneman DL, Neu HC, et al. Elimination of Staphylococcus aureus nasal carriage in health care workers: analysis of six clinical trials with calcium mupirocin ointment. Clin Infect Dis 1993;17:466-474.

18. Reagan DR, Doebbeling BN, Pfaller MA, et al. Elimination of coincident Staphylococcus aureus nasal and hand carriage with intranasal application of mupirocin calcium ointment. Ann Intern Med 1991;114:101-106.

19. Gilbart J, Perry CR, Slocombe B. High-level mupirocin resistance in Staphylococcus aureus: evidence for two distinct isoleucyl-TRNA synthetases. Antimicrob Agents Chemother 1993;37:32-38.

20. Barrett SP. The value of nasal mupirocin in containing an outbreak of methicillin-resistant $S$ aureus in an orthopaedic unit. $J$ Hosp Infect 1990;15:137-142.

21. Voss A, Milatovic D, Wallrauch-Schwartz C, Rosdahl VT, Braveny I. Methicillin-resistant Staphylococcus aureus in Europe. Eur J Clin Microbiol Infect Dis 1994;13:50-55.

22. Kauffman CA, Terpenning MS, He X, et al. Attempts to eradicate methicillin-resistant Staphylococcus aureus from a longterm care facility with the use of mupirocin ointment. Am J Med 1993;94:371-378.

23. Wenzel RP. Preoperative antibiotic prophylaxis. $N$ Engl J Med 1992;326:337-339.

\title{
New Test for Diagnosis of CJD
}

\section{Gina Pugliese, RN, MS Martin S. Favero, $\mathrm{PhD}$ Contributed by Russell M. Olmsted, MPH, CIC}

Transmissible spongiform encephalopathies (TSEs), including Creutzfeldt-Jakob Disease (CJD) and kuru in humans, scrapie in sheep, and, most recently, bovine spongiform encephalopathy (BSE) in cattle, cause neurodegeneration that culminates in death. The TSEs have been in the news of late because of the observation of a cluster of unique pathologic presentations of CJD among young adults in the United Kingdom in the latter half of 1995. Previously, most sporadic cases of CJD occurred among persons over the age of 45 . Concerns have been raised that this new variant form of CJD might be associated with coincident observation of BSE among cattle in the United Kingdom. To date, this remains hypothetical. Diagnosis traditionally relies on brain biopsy, because noninvasive imaging and clinical symptoms associated with advanced disease are nonspecific. As such, a screening test for TSEs would be extremely helpful for diagnosis.

Two recent encouraging reports have offered hope that an assay for TSE may be developed. Hsish and colleagues have developed an immuno- assay used on cerebrospinal fluid that detects a protein, 14-3-3, that is released when neurons are destroyed by prion diseases such as CJD. ${ }^{1}$ It has a high sensitivity (96\%) and specificity (98\%) for human (and animal) TSEs. False-positive results were seen in patients with viral encephalitis and recent cerebral infarct. In a letter to the editor in Lancet, Will and colleagues described the results of a study that reinforced the usefulness of this CSF 14-3-3 protein immunoassay test. ${ }^{2}$ The spinal fluid of 40 definite or probable CJD cases, including sporadic, familial, iatrogenic, and the new variant $\mathrm{CJD}$, were tested using the CSF 14-3-3 protein immunoassay test. Optimal specimen handling prior to testing is to freeze immediately and store at $<4^{\circ} \mathrm{C}$. Results for the 40 specimens were separated for frozen specimens (optimal) and nonfrozen (suboptimal) specimens. For the optimal specimens, the CSF 14-3-3 test was positive in six of seven cases of definite or possible CJD, including two cases of nonvariant CJD. The test missed one case of iatrogenic CJD, but, clinically, the patient was in the early stages of illness. For the suboptimal CSF specimens, the test was positive in four definite or probably sporadic cases of CJD and in one familial CJD case, but gave a false negative in two definite and one possible case of nonvariant CJD. False positives also were seen in two of eight cases of nonCJD illnesses. In a separate study, Zerr and colleagues reported on another test to screen for CJD: a modified, two-dimensional, gel electrophoresis technique for detection of two different proteins, p130/131, released by the effects of CJD. ${ }^{3}$ Using this technique, the positive predictive value was $100 \%$, and the negative predictive value was $69 \%$. The twodimensional gel electrophoresis method is technically complex to perform therefore and has not been offered by most clinical laboratories. For both of these assays, it is not clear how soon they become positive in the course of CJD, thus their application for screening humans and animals remains to be elucidated.

FROM: 1. Hsish G. Kenny K, Gibbs CJ, Lee KH, Harrington MG. The 14-3-3 brain protein in cerebrospinal fluid as a marker for transmissible spongiform encephalopathies. N Engl J Med 1996;335:924-930.

2. Will RG, Zeidler M, Brown $P$, et al. Cerebrospinal fluid test for newvariant Creutzfeldt-Jakob disease. Lancet 1996;348:955. Letter.

3. Zerr I, Bodemer M, Otto M, et al. Diagnosis of Creutzfeldt-Jakob disease by two-dimensional gel electrophoresis of cerebral spinal fluid. Lancet 1996;348:846-849. 